\title{
Smart educations (Impacts of technology on student learning)
}

\author{
Mohammed Al-Masoudi
}

MIDDLE EAST COLLEGE

\begin{abstract}
The proposed project will be categorized under digital education. It connects teachers and students in the country under one digital platform. It is important to note that education is the main root of economic development and improvement of living standards. As the global economic competition becomes stiffer, then, also education becomes an important source of competition since it is linked to economic development. When the level of education in a country is improved, it attracts students globally to come and study in the country and also it attracts investors. When there is a well-skilled and educated workforce in a country, then it creates a strong pillar to a knowledge-based economy. This has made the education sector to implement new reforms in the education system. The new reforms are to ensure that the country is able to face the prevailing political, social, economic, and technological changes.
\end{abstract}

\section{Introduction}

The proposed project will be categorized under digital education. It connects teachers and students in the country under one digital platform. It is important to note that education is the main root of economic development and improvement of living standards. As the global economic competition becomes stiffer, then, also education becomes an important source of competition since it is linked to economic development. When the level of education in a country is improved, it attracts students globally to come and study in the country and also it attracts investors. When there is a well-skilled and educated workforce in a country, then it creates a strong pillar to a knowledge-based economy. This has made the education sector to implement new reforms in the education system. The new reforms are to ensure that the country is able to face the prevailing political, social, economic, and technological changes.

Many countries have always embraced the introduction of the use of information technologies in the education sector. Introduction of information technology leads to improved quality of education since the students have advanced materials to perform their research. Also, the world economy has shifted to a knowledge-based economy, and this requires the education system to develop individual ability to apply knowledge in a dynamic context. Information technology has been mandated to ensure that the education system has attained these objectives. Providing quality education in Oman to the students in both rural and urban areas has been a major challenge. Today it is becoming difficult to maintain and work using paperwork or even handling data and information manually. Systems can be implemented to maintain daily records according to the student's requirements.

\section{Aims and objectives of Smart Education system}

- To Design scalable and relabel network

- To Provide coactivity between ministry and schools

- To Implement the cloud beset learning management system

- To have all the books, exams, and assignments under one platform. 
- To have a system that works conveniently, allowing access to data and information online.

- To develop a system that eliminates the use of hard copied books

- To provide a system that is easily accessible by many students despite their location.

- To introduce smart classrooms in the education system

- Creating a good relationship between the education ministry and the schools

To have a scalable and reliable network design The increase in the number of computing devices in the world has led to the innovation of smart technological systems. A smart education system is a form of technology that will be implemented and utilized to help students in learning by providing a flexible mode of learning. The system will be using technology as a tool for accessing learning resources through inquiry, communication, and collaboration, expression, and evaluation. When technologies connect people, then, this becomes a major Smart Education System paradigm. This system will emphasize utilizing computing devices and networking techniques to obtain data from the ministry's server. On the other side, mobile devices and laptops will be utilized to enhance learning mobility. It will help to change the education system by ensuring that learning takes place anytime and anywhere despite time, environment, and location differences.

The smart education framework of one school in United States

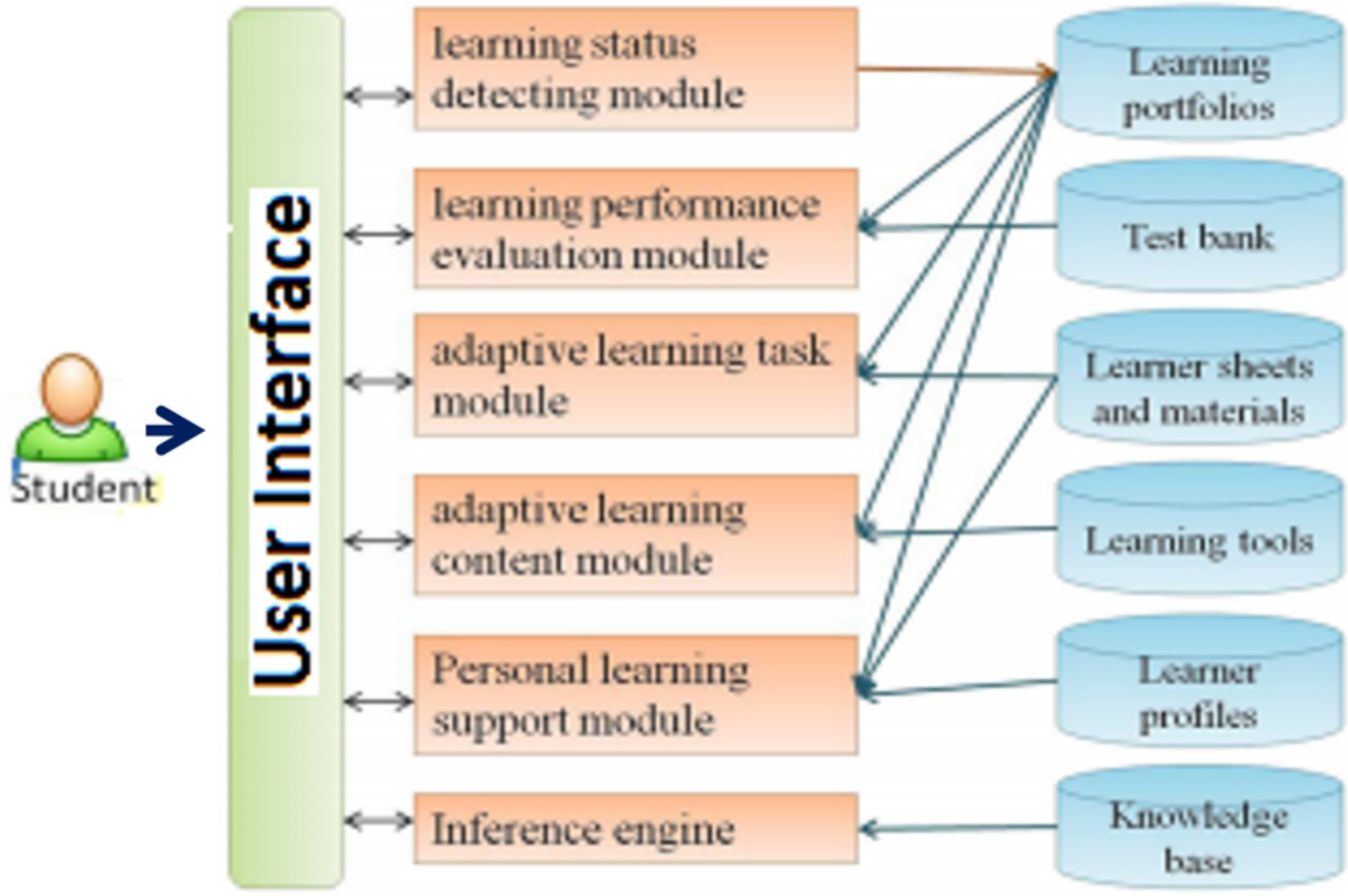


Figure 1. The smart education framework of one school in China

\section{A Framework for Smarter Education (Zhu Zhiting, 2012)}

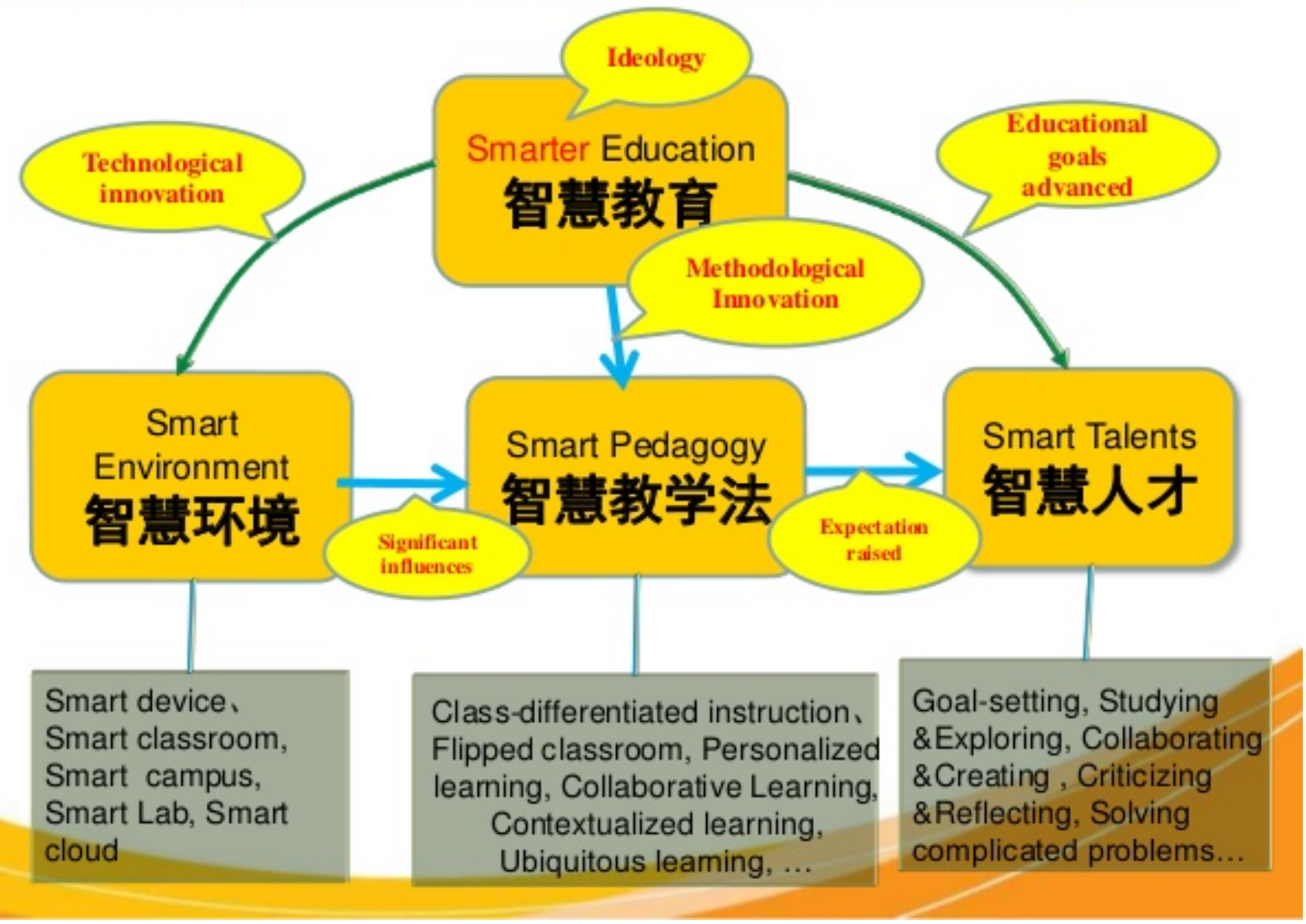

Figure 2. A Framework for Smarter Education

\section{References}

Bidgoli, H. (2007). The Handbook of Computer Networks, LANs, MANs, WANs, the Internet, and Global, Cellular, and Wireless Networks. Wiley.

Chang, M., \& Li, Y. (2014). Smart Learning Environments. Basingstoke, England: Springer.

Darshan Singh, A., Raghunathan, S., Robeck, E., \& Sharma, B. (2018). Cases on Smart Learning Environments. Hershey, PA: IGI Global.

Eisenbach, B. B., \& Greathouse, P. (2018). The Online Classroom: Resources for Effective Middle Level Virtual Education. Charlotte, NC: IAP.

Holmes, B., \& Gardner, J. (2006). E-Learning: Concepts and Practice. SAGE.

Horton, W. (2011). e-Learning by Design. Hoboken, NJ: John Wiley \& Sons.

Hussain, I. (2007). A Study of Students' Attitude Towards Virtual Education in Pakistan. 
Kwan, R. (2008). Enhancing Learning Through Technology: Research on Emerging Technologies and Pedagogies. Toh Tuck Link, Singapore: World Scientific.

Popescu, E., Kinshuk, Khribi, M. K., Huang, R., Jemni, M., Chen, N., \& Sampson, D. G. 